\title{
THE 5th AFIR INTERNATIONAL COLLOQUIUM
}

The city of Brussels, official capital of Belgium and unofficial capital of Europe, provided the splendid backdrop for the 5th AFIR Colloquium. The choice of the Sheraton Hotel as the venue and, in particular, its 30 th floor restaurant where participants had two excellent lunches, ensured that, when the clouds parted, everyone was able to enjoy many of the delights of the city without having to leave their seat.

For some the meeting provided an all-too-short but vigorous and technical warm-up for the 25 th International Congress of Actuaries. For many others, however, the Colloquium was sufficient in itself. The Colloquium started off with an invited lecture given by Professor Hans Bühlmann and entitled "Collective Risk Theory for Assets". Professor Bühlmann introduced his talk by describing how financial economists had contributed to the field of actuarial science. He then moved on to discuss how actuaries could return the favour by applying collective risk theory to the theory of finance.

The particular problem discussed related to the actuarial valuation of a portfolio of assets and, in particular, a distribution-free approach to the selection of what actuaries might describe as a valuation rate of interest. The first step involved the setting of a Risk Level, $R$ : a quantity which is known in another context as the Adjustment Coefficient. The Risk Theoretical Growth Rate (or valuation rate of interest) could then be defined in terms of $R$ and the empirical distribution of future returns. By increasing $R$ one would lower the Risk Theoretical Growth Rate and consequently lower the simple-to-calculate probability that the actual value of a portfolio falls below a specified lower bound: an event similar to "ruin" in risk theory.

The second invited lecture was given by Jean Berthon, Chairman of the Institut des Actuaires Français. His talk was entitled "The Actuary and the Measurement of Banks' Market Risks". The focus of this talk rested on the recent guidelines provided by the Basle committee for banks' evaluation of solvency margins. These guidelines rely heavily on banks' own computer models and the talk discussed this point and the involvement of actuaries in the future development of such models. One slide illustrating the one-off, large losses sustained by some banks clearly demonstrated that many banks still have a long way to go.

The contributed sessions contained nearly sixty papers, although a significant number of the authors were not present at the meeting to introduce their works: a problem which created an imbalance between some sessions. The titles of the four topics meant that the meeting was directed more towards mathematical finance than actuarial applications. This did not, however, prevent some contributors from sneaking in some liability modelling on the side. The four topics were: Arbitrage and Hedging of Derivatives; Deregulation of the Markets and of Financial Intermediaries; The Dynamics of Interest Rates; and The Use of Derivatives for the Management of Financial Institutions. 
Topic 1 contained papers which considered methods for pricing a wide variety of derivative products. Some papers discussed the general approach to such problems while others provided a variety of solutions to more specific products.

Topic 2 considered how risk management within many different types of financial institution might evolve in response to the relaxation of investment and other regulations. Papers looked at such diverse areas as Bancassurance, catastrophe insurance and pension funding. The importance of problem formulation was indirectly highlighted in the latter case when two consecutive speakers proposed diametrically opposed portfolio insurance strategies: this being the result of each having specified different objectives.

Topic 3 focused broadly on aspects of models for the term structure of interest rates. At one end of the spectrum papers discussed the theoretical formulation and solution of models for interest rates and bond prices. At the more practical end the problem of parameter estimation when the data have a different structure to the model.

Topic 4 considered how derivatives could be used to control risk in financial institutions. Some papers considered general portfolio theoretical problems while others focused specifically on, for example, life insurers.

The 5th AFIR colloquium saw the introduction of the first International AFIR prize. Four authors were selected for consideration by the prize committee and their papers were presented in a special session at the end of the first day. The winners were David Cummins and Hélyette Geman for their paper "An Asian Option Approach to the Valuation of Insurance Futures Contracts". This paper described the authors' pioneering work in the application of existing approaches to the pricing of financial derivatives to the relatively new field of insurance futures. Second prizes went to Griselda Deelstra for her paper on interest rate modelling and to Edwin Neave for his efficient approach to the valuation of price average options. The third prize was awarded to Glen Harris for his work on ERCH models.

The proceedings were brought to a conclusion with a round table discussion on financial risk management in insurance companies, led by an international panel of experts.

The high quality of the technical sessions was matched by the occasion of the closing dinner. This was held in a beautiful Art Nouveau building housing the Musée de la Bande Dessinée (Comic Strip Museum). Seeking out one's lost youth amongst a multitude of images of Tintin and Captain Haddock provided an excellent way of relaxing after the intellectual rigours of the previous two days.

\author{
ANDREW J.G. CaIrns \\ Department of Actuarial Mathematics and Statistics, \\ Heriot-Watt University, \\ Riccarton, Edinburgh, EH14 4AS, \\ United Kingdom
}

